IP Periodica Polytechnica

Mechanical Engineering

61(1), pp. 74-78, 2017

DOI: $10.3311 /$ PPme. 10060

Creative Commons Attribution (i)

RESEARCH ARTICLE

\section{Effect of Fiber Contents on Fatigue Behavior of Injection Molded Polyamide 6 Matrix Composites}

\author{
József Szakács ${ }^{1 *}$, László Mészáros ${ }^{1,2}$
}

Received 23 September 2016; accepted after revision 09 December 2016

\begin{abstract}
In this study the effect of basalt and carbon fiber content on quasi-static and fatigue mechanical properties of polyamide 6 are investigated. Composites with different fiber contents were melt compounded, then specimens were injection molded. The presence of basalt and carbon fiber caused significant change in tensile properties; the effect of carbon fibers was major as expected. Fatigue life of composites decreased compared to the neat matrix, but it should be mentioned that higher load was applied in case of composites. Carbon fibers had remarkable effect on the decrement of cyclic creep. This means that the deformation of carbon fiber reinforced composites was lower than that of basalt fiber composites, even if load level was higher. Scanning electron microscopy of the fracture surfaces revealed larger tough fracture surface for carbon fiber reinforced composites compared to the basalt fiber reinforced ones.
\end{abstract}

\section{Keywords}

polyamide 6, carbon fiber, basalt fiber, fatigue

\footnotetext{
${ }^{1}$ Department of Polymer Engineering, Faculty of Mechanical Engineering, Budapest University of Technology and Economics,

Muegyetem rkp. 3., H-1111 Budapest, Hungary

${ }^{2}$ MTA-BME Research Group for Composite Science and Technology,

Muegyetem rkp. 3., H-1111 Budapest, Hungary

*Corresponding author, e-mail: szakacs@pt.bme.hu
}

\section{Introduction}

Performance improvement is one of the most important criteria when a novel polymer composite is developed for engineering applications. For the optimal mechanical performance of materials composite industry uses several types of reinforcing materials [1]. The popularity of glass fibers is unbroken, but nowadays carbon fiber is gathering ground, thanks to its decreasing price and well known good mechanical properties [2-4]. Another competitor is basalt fiber. Its composition is close to glass fiber, but this eruptive rock has less complex structure, its thermal and chemical resistance is much better and production is simpler compared to widely used E-glass fiber [5, 6]. As well as glass fibers basalt fibers appeared not only as reinforcement of polymer matrices but also in concretes [7, 8].

Because of the high performance and the mass production the fiber reinforced plastics are becoming increasingly popular in the automotive industry. These composites usually suffer fatigue load, that is why it is important to investigate the fatigue properties of a new type of composite. More and more researchers assume that not just the fatigue life of a material is important but also the failure process itself, therefore researchers pay more attention to the investigation of fatigue crack propagation and failure analysis [9-14].

Esmaelliou et al. [14] investigated the fatigue properties of glass fiber reinforced polyamide 66, where the load factor which is the ratio of minimal and maximal stress was 0.1 and frequency was $20 \mathrm{~Hz}$. They showed that the fatigue process during loading of polyamide 66 can be divided into three parts. In the first part the relative Young's modulus decreases intensively and temperature increases gradually. Then in the second part, both the temperature and the relative modulus are approximately constant. The third part begins typically when $75 \%$ of the number of cycles that belongs to failure is reached. In this part temperature increases and relative modulus decreases again until failure. At higher load levels the second and the third part become less remarkable and gradually disappear by further load increment.

There are only a few publication that deals with the investigation of fatigue properties of injection molded thermoplastic 
Table 1 Fiber content, tensile strength measured at high speed and maximal loads used during fatigue tests (PA6 / BF - basalt fiber reinforced composites, PA6 / CF carbon fiber reinforced composites)

\begin{tabular}{lllllll}
\hline Material name & $\begin{array}{l}\text { Basalt fiber } \\
{[\mathrm{wt} \%]}\end{array}$ & $\begin{array}{l}\text { Carbon } \\
\text { fiber [wt\%] }\end{array}$ & $\begin{array}{l}\text { Tensile strength } \\
{[\mathrm{MPa}]}\end{array}$ & $\begin{array}{l}\text { Maximal load } \\
\text { at 90\% [MPa] }\end{array}$ & $\begin{array}{l}\text { Maximal load } \\
\text { at 85\% }[\mathrm{MPa}]\end{array}$ & $\begin{array}{l}\text { Maximal load } \\
\text { at } 80 \%[\mathrm{MPa}]\end{array}$ \\
\hline PA6 & - & - & $77.9 \pm 1.2$ & 70.1 & 66.2 & 62.3 \\
PA6 / 10 BF & 10 & - & $105.2 \pm 0.7$ & 94.7 & 89.4 & 84.2 \\
PA6 / $20 \mathrm{BF}$ & 20 & - & $123.7 \pm 2.1$ & 111.3 & 105.1 & 99.0 \\
PA6 / 30 BF & 30 & - & $136.4 \pm 1.4$ & 122.8 & 115.9 & 109.1 \\
PA6 / 10 CF & - & 10 & $111.9 \pm 1.1$ & 100.7 & 95.1 & 89.5 \\
PA6 / 20 CF & - & 20 & $168.6 \pm 1.6$ & 151.7 & 143.3 & 134.9 \\
PA6 / 30 CF & - & 30 & $205.8 \pm 0.9$ & 185.3 & 175.0 & 164.7 \\
\hline
\end{tabular}

polymer composites. The majority of these contributions deals with glass fiber reinforcement and usually the mechanical characterization is carried out at only one fiber content.

The aim of the present study is to produce composites with different basalt and carbon fiber contents, and explore their impact on fatigue performance. For the examination of the fatigue process the cyclic creep was determined and the fracture surfaces were investigated.

\section{Materials and methods \\ 2.1 Materials}

Schulamid 6 MV 13 type polyamide 6 (PA 6) from A. Schulman GmbH (Germany) was used as matrix material. BCS KV12 type basalt fiber (BF) from Kamenny Vek Ltd. (Russia), and Panex 35 Type 95 carbon fiber (CF) from Zoltek Zrt. (Hungary) were applied as reinforcement. Starting length of both fibers was $6 \mathrm{~mm}$. The basalt fiber diameter was $15.6 \pm 1.9 \mu \mathrm{m}$ and the carbon fiber diameter was $8.3 \pm 1 \mu \mathrm{m}$.

\subsection{Sample preparation}

A Labtech Scientific type twin screw extruder $(\mathrm{L} / \mathrm{D}=44$; $\mathrm{D}=26 \mathrm{~mm}$ ) was used for continuous melt mixing. The screw speed was $251 / \mathrm{min}$ and the extrusion temperature was $250^{\circ} \mathrm{C}$. For the different composites 10, 20 and $30 \mathrm{wt} \% \mathrm{BF}$ or $\mathrm{CF}$ was used. Composite names and reinforcement contents can be followed in Table 1 . Dried PA 6 granulates $\left(80^{\circ} \mathrm{C} ; 4\right.$ hours $)$ were mechanically mixed with the reinforcing materials, then extruded and granulated (particle size: $4.5 \mathrm{~mm}$ ). Dumbbell type specimens (4x10 $\mathrm{mm}$ cross section) were injection molded (injection molding temperature was $275^{\circ} \mathrm{C}$, mold temperature was $80^{\circ} \mathrm{C}$, and maximal pressure was 800 bar) on an Arburg Allrounder Advance 370S 700-290 injection molding machine.

\subsection{Characterization methods}

Before the mechanical tests, the specimens were conditioned at $50 \%$ relative humidity and $25^{\circ} \mathrm{C}$ for a week. Tensile tests were performed on a Zwick Z020 universal testing machine. Before the fatigue tests high speed tensile tests (crosshead speed: $200 \mathrm{~mm} / \mathrm{min}$ ) were performed to determine the load levels.
Fatigue tests were carried out on an Instron 8872 hydraulic tensile testing machine equipped with Instron 2742-301 type hydraulic grips. The load-controlled fatigue tests were performed under tension-tension load with sinusoidal waveform. The excitation frequency was $2 \mathrm{~Hz}$ and the load factor was $\mathrm{R}=0.1$ ( $\mathrm{R}=$ maximum stress/minimum stress). The temperature of the specimen surface was measured with a FLIR A325sc infrared camera. During the tests, the area of the whole surface was inspected and the highest temperature was registered.

The fracture surfaces of the broken fatigue tested specimens were investigated with a Jeol 6380 LA type scanning electron microscope (SEM) after sputtering them with a thin gold layer. For the fracture surface ratio analysis 10 pictures were taken from the broken face of a specimen (3 specimens from each composite). These pictures were stitched with Hugin 2014.0.0. software (every reference check points were reviewed). The area of the fracture surface, and the tough region was measured with an image analyzer software. The borderline between the rigid and the tough surfaces were marked manually, where the borders scatter were 2 pixels, and this error was added to the measured values.

\section{Results and discussion}

\subsection{Tensile properties}

Results of the high speed tensile tests showed that basalt and carbon fibers increased the tensile strength of composites (Table 1). Tensile strength of CF composites was higher without exception than that of composites with basalt fiber. At 30 $\mathrm{wt} \%$ fiber content the tensile strength of $\mathrm{CF}$ composites reached 205.8 MPa, while maximum value of basalt fiber composites was only $136.4 \mathrm{MPa}$. The result reached with carbon fiber is unique among composites made from thermoplastic polymers.

\subsection{Fatigue tests}

The applied loads for fatigue tests were calculated from the results of tensile tests. Relatively high load was applied (Table 1-load levels marked after the material name on figures). The nonlinear fatigue life of the neat matrix met the expectations and can be seen in Fig. 1a. To examine the structure-property 


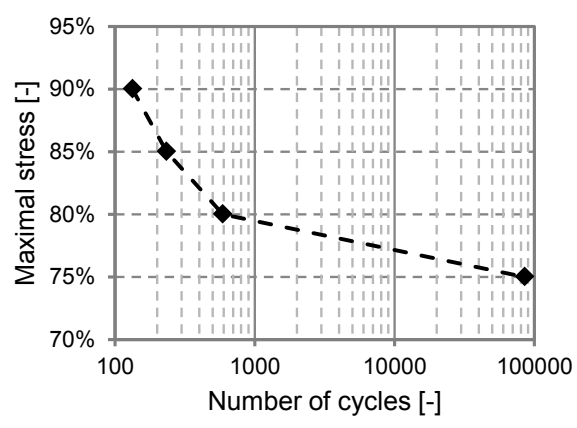

a)

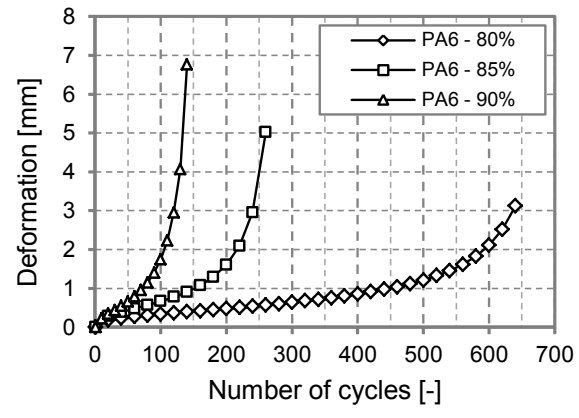

b)

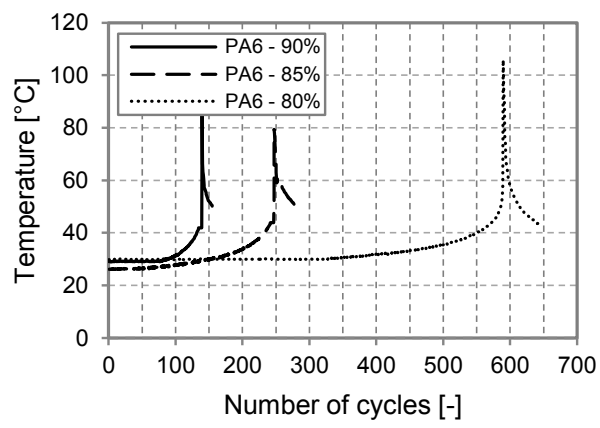

c)

Fig. 1 Polyamide 6 fatigue tests results: a) Stress - Number of cycles curve, b) cyclic creep of the material at different loads, c) temperature of the specimen at different loads

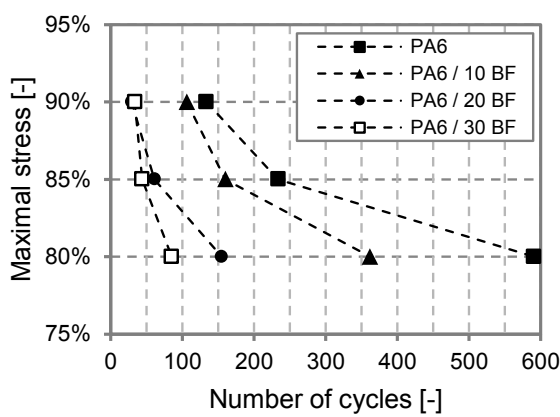

a)

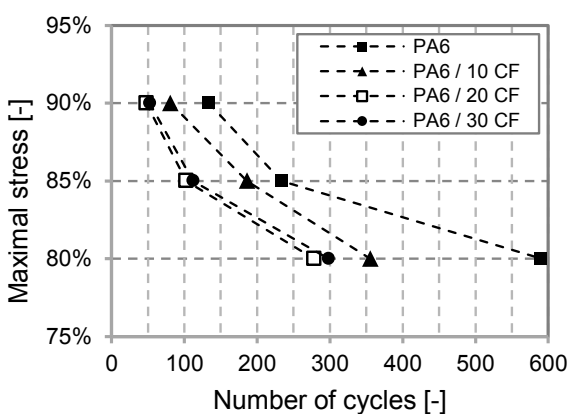

b)

Fig. 2 S-N curve at different load levels: a) basalt fiber reinforced composites, b) carbon fiber reinforced composites

relationships during fatigue tests, temperature of specimens were registered in each cycle. Temperature change is relevant because one part of the deformation energy develops into heat, this results in local temperature rise thanks to the good heat insulating properties of polymers. Increasing temperature has effect on the mechanical properties, for example it usually reduces the Young's modulus. In case of PA6 the temperatures and deformations moderately ascended in the first period of fatigue test (Fig. 1b and c). To monitor cyclic creep momentary elongation in certain cycles were measured. The deformation increment in the first cycles can be connected to instantaneous elastic deformation, and time-dependent viscoelastic deformation, while in a later period of fatigue life residual deformation can be observed as the slow increment of deformation, This phenomenon can be explained by the creeping of the polymeric materials at static loads as the fatigue test was carried out in tensile-tensile mode, therefore the specimens were under continous load. [15]. Before breakage temperature increased faster and at the moment of failure temperature, as well as deformation suddenly increased (Fig. 1). Presumably, not the temperature rise initialized failure, it only accompanied failure inside the material. On one hand, the increased deformation caused more energy to develop into heat, and on the other hand crack propagation resulted in a considerable heat release, too.
Composites broke earlier compared to neat polyamide 6, and that can be explained by the effect of higher loading force (Fig. 2a, b). In case of both basalt and carbon fiber reinforced composites the fiber content had negative influence on fatigue life, that means during fatigue tests matrix deformation and failure are dominant. At higher test forces crack propagation in the matrix was faster, and that brought forward the failure of the specimens, hence the tensile strength of the material was higher in vain. Only in case of $30 \mathrm{wt} \%$ carbon fiber content another effect was observed. The cycle number was nearly the same as in case of composites reinforced with $20 \mathrm{wt} \%$ carbon fiber.

Temperature increase in composites was continuous and faster than in the neat matrix (Fig. 3a and b). Temperature changed in the whole specimen that means failure was in progress in the whole material as it was observed in previous studies [11-14]. The failure mechanism was too fast to reach a balanced state as Esmaelliou et al. [14] reported. At the moment of failure temperature suddenly increases since during crack propagation the energy stored in the elastic deformation components is released, and a new surface is created with its help. This process raised the specimen temperature. Positive effect of high carbon fiber content was revealed here, and in case of composites with $20 \mathrm{wt} \%$ and $30 \mathrm{wt} \% \mathrm{CF}$ the temperature change was nearly the same. That means failure process is 


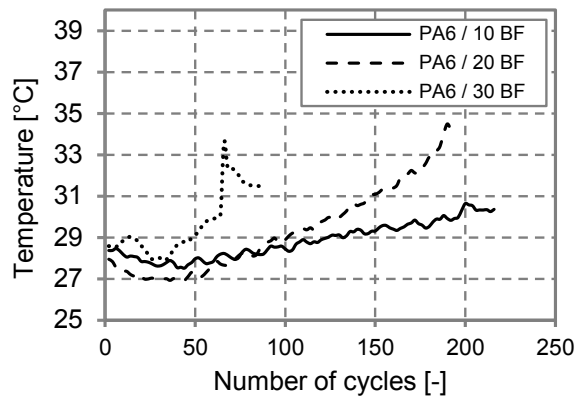

a)

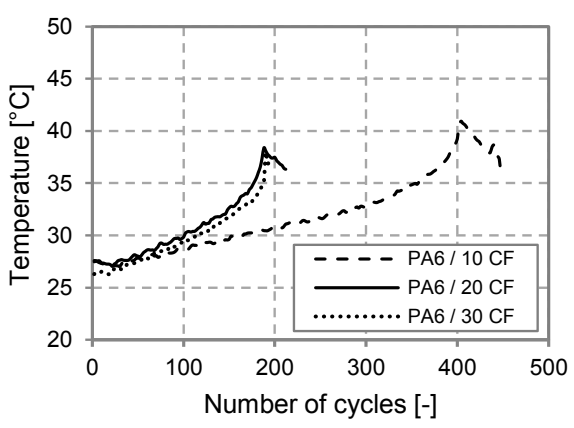

b)

Fig. 3 Temperature of basalt fiber reinforced composites (a) and carbon fiber reinforced composites (b) during fatigue test carried out at $80 \%$ of tensile strength

similar at different loading forces, which can be explained by the increased heat conducting behavior. At higher carbon fiber contents fibers are able to conduct the heat generated in the failure zone to the other part of the specimen which results in lower and similar temperature increase at the fracture.

Besides fatigue life, creeping or cyclic creeping of polymers are also important properties. Therefore, the deformation of all composites was measured, and compared. Due to high loads deformation was large, and cyclic creeping was relatively fast. Cyclic creep of carbon fiber reinforced composites was less than that of basalt fiber composites (Fig. 4), at every fiber content and load level.

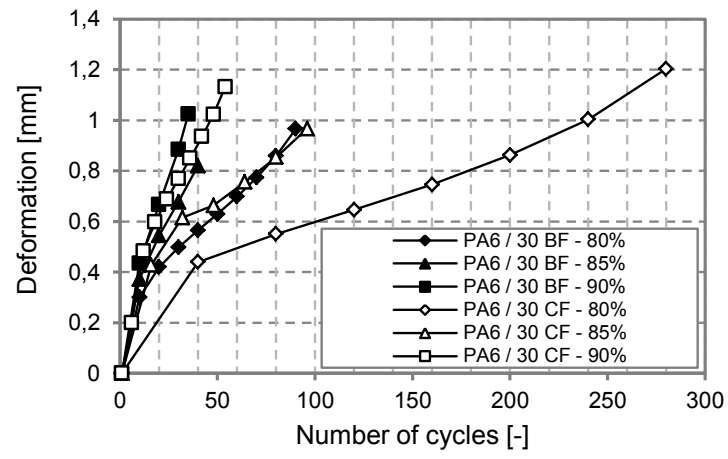

Fig. 4 Cyclic creep of composites with $30 \mathrm{wt} \%$ basalt and carbon fiber content at different load levels

That means carbon fiber composites could have substantially smaller deformation compared to basalt fiber composites at the same load level. This effect can be explained by the better mechanical properties of carbon fibers, for example the much higher Young's modulus than that of glass or basalt fibers [15] and the better fiber-matrix adhesion. This could not be the effect of better sizing alone, but also a result of the higher length/ diameter ratio and larger surface roughness, which means higher bonding surface in favor of carbon fiber. To examine failure energy demands, the fracture surface of the composites was investigated by SEM. This investigation follows the failure mechanism described by Horst et al. [11]. Firstly, the cracks appear at the end of fibers because they are stress concentration points, then the crack grows along fibers, and finally these areas of failure connect to each other and create voids. This tough breakage is dominant until a critical size is reached, when the test ends with a sudden and catastrophic rigid breakage. Therefore, in favorable cases the fracture surfaces can be divided into a tough and a rigid part as it can be seen in Fig. 5a. In the picture part A is tough and part B is rigid, and between the two areas a relatively sharp borderline can be defined.

If only the rigid part can be observed, it means the material is too rigid, or the speed of loading was too high for stable fracture propagation. That happened at lower basalt fiber contents $(10 \mathrm{wt} \%$ and $20 \mathrm{wt} \%)$. At $30 \mathrm{wt} \%$ basalt content and in case of all carbon fiber composites two types of fracture surfaces were observed, and the ratio of surfaces can be studied in Table 2 . The tough fracture surface ratio increased when load decreased, because the critical crack size is higher at lower loading forces. The important result is that larger tough fracture surface was found in case of higher carbon fiber content. This proves that higher carbon fiber content increases the energy consumption of crack propagation.

Table 2 On different load level fatigued composites tough fracture surface ratio (ratio of tough and full fracture surface)

\begin{tabular}{llll}
\hline Material name & $\begin{array}{l}\text { Tough surface } \\
\text { ratio [\%] }\end{array}$ & Material name & $\begin{array}{l}\text { Tough surface } \\
\text { ratio [\%] }\end{array}$ \\
\hline PA6/ 10BF 80\% & - & PA6/ 10CF 80\% & $11.7 \pm 1.8$ \\
PA6/ 10BF 90\% & - & PA6/ 10CF 90\% & $1.2 \pm 2.3$ \\
PA6/ 20BF 80\% & - & PA6/ 20CF 80\% & $18.6 \pm 1.3$ \\
PA6/ 20BF 90\% & - & PA6/ 20CF 90\% & $8.1 \pm 1.8$ \\
PA6/ 30BF 80\% & $22.2 \pm 1.0$ & PA6/ 30CF 80\% & $24.2 \pm 1.0$ \\
PA6/ 30BF 90\% & $12.8 \pm 1.4$ & PA6/ 30CF 90\% & $8.3 \pm 1.3$ \\
\hline
\end{tabular}




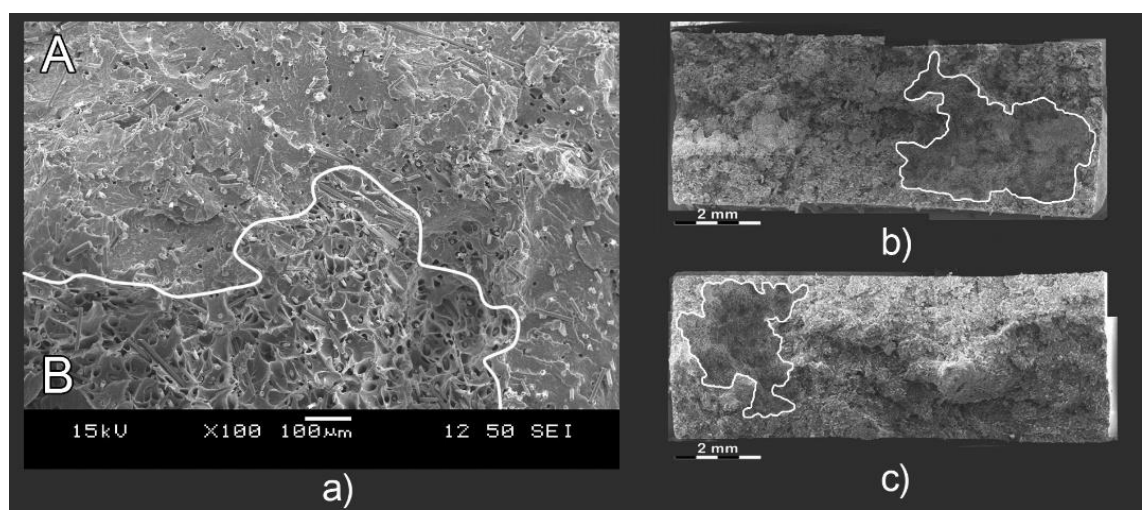

Fig. 5 Fracture surfaces of basalt fiber reinforced composites (a) after fatigue test carried out at $80 \%$ (b) and $90 \%$ (c) of the tensile strength (tough fracture surface inside the white border)

\section{Conclusions}

In this study fatigue behavior of PA 6 matrix composites was investigated. The tensile test results showed that the presence of basalt and carbon fiber increased the tensile strength of composites significantly. During low-cycle fatigue tests composites with high fiber content had significantly smaller fatigue life. This can be explained by the higher loading force. Fibers decreased the cyclic creep of the material, and this effect was more significant in case of carbon fibers. After the fatigue test the rigid/tough ratio of the fracture surface was examined with SEM. It revealed that the higher fiber content increased the proportion of the tough surface, and that means the rise of crack propagation energy demands. In conclusion, carbon fibers have remarkable positive effect not only on the classic mechanical properties like tensile strength, but also on the fatigue life of the material compared to the popular glass/basalt fibers. These properties and its decreasing price make carbon fiber a reinforcement preferred by industry.

\section{Acknowledgements}

This research was realized in the frames of TÁMOP 4.2.4.A/111-1-2012-0001 „National Excellence Program - Elaborating and operating an inland student and researcher personal support system" The project was subsidized by the European Union and co-financed by the European Social Fund. This research was also supported by the Hungarian Research Fund (OTKA PD105564). This paper was supported by the János Bolyai Research Scholarship of the Hungarian Academy of Sciences.

\section{References}

[1] Rosato, V. D., Rosato, V. D. "Reinforced Plastics Handbook." Third ed., Elsevier A. T., Oxford. 2004.

[2] Mouhmid, B., Imad, A., Benseddiq, N., Benmedakhéne, S., Maazouz A. "A study of mechanical behaviour of a glass fiber reinforced polyamide 6,6: Experimental investigation." Polymer Testing. 25, pp. 544-552. 2006. https://doi.org/10.1016/j.polymertesting.2006.03.008

[3] Wu, S.-H., Wang, F.-Y., Ma, C.-C. M., Chang, W.-C., Kuo, C.-T., Kuan, H.-C., Chen, W.-J. "Mechanical, thermal and morphological properties of glass fiber and carbon fiber reinforced polyamide- 6 and polyamide- $6 /$ clay nanocomposites." Materials Letters. 49, pp. 327-333. 2001. https://doi.org/10.1016/S0167-577X(00)00394-3
[4] Nevin, G. K., Ayse, A. "Tensile and thermomechanical properties of short carbon fiber reinforced polyamide 6 composites." Composites Part B. 51, pp. 270-275. 2013.

https://doi.org/10.1016/j.compositesb.2013.03.023

[5] Deák, T., Czigány, T., Tamás, P., Németh, Cs. "Enhancement of interfacial properties of basalt fiber reinfroced nylon 6 matrix composites with silane coupling agents." eXPRESS Polymer Letters. 4, pp. 590-598. 2010. https://doi.org/10.3144/expresspolymlett.2010.74

[6] Fiore, V., Scalici, T., Bella Di, G., Valenza, A. "A review on basalt fiber and its composites." Composites Part B. 74, pp. 74-94. 2015.

https://doi.org/10.1016/j.compositesb.2014.12.034

[7] Weimin, L., Jinyu, X. "Mechanical properties of basalt fiber reinforced geopolymeric concrete under impact loading." Materials Science and Engineering A. 505, pp. 178-186. 2009.

https://doi.org/10.1016/j.msea.2008.11.063

[8] Kizilkant, A. B., Kabay, N., Akyüncü, V. , Chowdhury, S., Akca, A. H. "Mechanical properties nad fracture behavior of basalt and glass fiber reinforced concrete: An experimental study." Construction and Building Materials. 100, pp. 218-224. 2015.

https://doi.org/10.1016/j.conbuildmat.2015.10.006

[9] Bernasconi, A., Davoli, P., Basile, A., Filippi, A. "Effect of fibre orientation on the fatigue behaviour of a short glassfibre reinforced polyamide-6." International Journal of Fatigue. 29, pp. 199-208. 2007. https://doi.org/10.1016/j.ijfatigue.2006.04.001

[10] Arif, M. F., Saintier, N., Meraghni, F., Fitoussi, J., Chemisky, Y., Robert, G. "Multiscale fatigue damage characterization in short glass fiber reinforced polyamide-66." Composites Part B. 61, pp. 55-65. 2014. https://doi.org/10.1016/j.compositesb.2014.01.019

[11] Horst, J. J., Spoormaker, J. L. "Fatigue fracture mechanisms and fractography of short-glassfibre-reinforced polyamide 6." Journal of Material Science. 32, pp. 3641-3651. 1997. https://doi.org/10.1023/a:1018634530869

[12] Bernasconi, A., Davoli, P., Armanni, C. "Fatigue strength of a clutch pedal made of reprocessed short glass fiber reinforced polyamide." International Journal of Fatigue. 32, pp. 100-107. 2010. https://doi.org/10.1016/j.ijfatigue.2009.02.001

[13] Launay, A., Maitournam, M. H., Marco, Y., Raoult, I., Szmytka, F. "Cyclic behaviour of short glass fiber reinforced polyamide: Experimental study and constitutive equations." International Journal of Plasticity. 27, pp. 1267-1293. 2011. https://doi.org/10.1016/j.ijplas.2011.02.005

[14] Esmaeillou, B., Fitoussi, J., Lucas, A., Tcharkhtchi, A. "Multi-scale experimental analysis of the tension-tension fatigue behavior of a short glass fibre reinforced polyamide composite." Procedia Engineering. 10, pp. 2117-2122. 2011. https://doi.org/10.1016/j.proeng.2011.04.350

[15] Ehrenstein, G. W. "Polymeric Materials." Carl Hanser V. München. 2001. https://doi.org/10.3139/9783446434134 